\title{
POTENTIALS OF ORGANIC AGRICULTURE IN NEPAL
}

\author{
Gopal Datt Bhatta (M Sc) ${ }^{1}$, Werner Doppler (PhD) and Krishna Bahadur KC (PhD)
}

\begin{abstract}
Increasing use of agro-chemicals, higher production cost and deteriorating ecosystem health have advocated the need to change traditional and external input use agriculture towards safe and sustainable organic production. Current research focuses on the constraints and opportunities of organic agriculture and consumers' awareness and willingness to pay more for organic vegetables by selecting producers from Lalitpur and Bhaktpur districts using spatial sampling and consumers from Kathmandu valley randomly. Data obtained from structured questionnaire were subjected to descriptive and econometric analysis and willingness to pay analysis. Most of the farmers interviewed are aware about the negative repercussion of the indiscriminate use of agro-chemicals. Organic vegetables are either home delivered and/or sold to the specialized niche markets. All domestic organic products reach to consumers without labeling. Most of the organic consumers are willing to pay eight rupees more for labeled organic vegetables. Currently organic farmers rely only on consumers' willingness to pay more to obtain a compensation for lower yields. Family income, education, profession etc are key attributes of the consumers shaping their decision to buy organic vegetables. Organic industry is too small and a long way to go in Nepal. Political commitments such as avoiding conflicting drive to maximize production, hammering proactive policy, initiating organic technology research, providing market incentives and institutionalization of Nepalese organic movement are imperative to further enhance organic sector in Nepal.
\end{abstract}

Key words: awareness, consumers, marketing, organic vegetables, regression, willingness to pay

\section{INTRODUCTION}

Environmental pollution and food safety due to chemical contamination become a great concern worldwide. Food and Agriculture Organization (FAO) proposed "The World Food Summit Plan of Action (1999)" in recognition with the importance of developing alternative sustainable agriculture such as organic farming. Organic farming is an integrated farming system which involved technical aspects (soil, agronomy, and weed and pest management) and economic aspects (input, output and marketing) as well as human health. Organic farming claims to have the potential to provide benefits in terms of environmental protection, conservation of non-renewable resources, improved food quality, reduction in output of surplus products and the reorientation of agriculture towards areas of market demand (Lampkin, 1990). Sharma (2001) makes a case for organic farming as the most widely recognized alternative farming system for sustainable production without seriously harming the environment and ecology. Veeresh (1999) opines that both high technology and sustainable environment cannot go together.

Since consumption of organic food products is the best remedy to prevent the numerous health hazards caused by conventionally produced foods, the global market has experienced exceptionally high growth in organic foods in the United States, Europe, and in other countries, yet market shares remain quite small (Piyasiri and Ariyawardana, 2002). However, in developing countries, the growth of organic sector is quite slow and faces tremendous challenges. Nepal's organic agricultural production has a relatively short history. Adoption of organic farming is quite slow, market for organic products is not well developed and no market statistics are available in Nepal (Bhatta et al., 2008a).

1 Institute of Agricultural Economics and Related Sciences in the Tropics and Sub-Tropics, University of Hohenheim, Stuttgart, Germany, Email: bhattagopal@gmail.com. 
Nevertheless, there is a growing trend among urban consumers to consume organic products from places where they could get an assurance about the quality of the products. Market features of organic products in Nepal show that it is still in the "formative stage" of the product life cycle (Bhatta et al., 2008a). Despite these facts, there are some rays of hopes among the organic producers and traders in the country.

Growth of organic agriculture requires producers' and consumers' awareness, availability of sound infrastructures and consumers' willingness to pay for the organic products. Nepal, being a developing country, definitely majority of the consumers is not well off. However, a large chunk of consumers are clustered in and around urban areas of the country and they could pay for the organic products provided quality is assured. Market potentials are mainly determined by consumer expectations of the product attributes, which are attached to the product such as quality (Ramesh et al., 2005), price (Roddy et al., 1996; Fotopoulos and Krystallis, 2002), certification (Kotler, 2001), price and quality (Boyle and Lathrop, 2009). Also consumers' awareness of health, food safety, environmental, and technology issues related to food products as well as the industrialization of agriculture and globalization, have been identified as diversification factors of food consumption (Senauer, 1994). Some empirical evidences regarding consumers' preference for differentiated quality attributes are given by Bhatta et al. (2008b), Bower and Baxter (2000), Elliott and Cameron (1994), Lans et al. (2001) and Okechuku (1994). There is the need to investigate wider perspective of organic farming through producers' and consumers' view point.

\section{OBJECTIVES}

The broad objective of this study is to find out the potentials of organic farming in Nepal with following specific objectives:

1. To study the level of awareness among the farmers and consumers about organic farming and organic products respectively;

2. To find out the preference of the consumers and their willingness to pay more for organic vegetables; and

3. To explore the constraints and potentials of organic farming through critical examinations of strengths, weaknesses, opportunities and threats.

\section{RESEARCH METHODOLOGY}

The study was conducted in different Village Development Committees (VDCs) of Lalitpur and Bhaktapur districts. It was supposed that these districts represent urban and periurban environment of Nepal and modestly developed, and farmers with different types of farming practices have been available. For consumers' survey, some of the organic and inorganic vegetable markets within the Kathmandu Valley such as The Organic Village, Bhatbhateni Supermarket, Sale ways Supermarket and Summit Hotel along with some local markets have been selected. After selecting study boundary, spatial sampling has been applied in selecting 130 respondents. Random selection approach while selecting 90 consumers was attempted as much as possible. The consumers were randomly approached at the market and asked for their participation in an interview. This procedure was applied due to lack of alternatives. However, not all of the selected consumers agreed to be interviewed and replacement of previously selected consumers occurred frequently. The non-response variables were simply ignored in the process of data analysis. 
Structured questionnaire was designed to collect primary information administered through interview and was pre-tested before executing interview. Collected data were subjected to descriptive and regression analysis. Additional willingness to pay analysis (AWTP) for different organic vegetable types was obtained by indicating the approximate prevailing prices of inorganically produced vegetables in the local markets as the base value. Strength, weakness, opportunities and threats (SWOT) analysis has also been rendered. Factors that influence the additional willingness to pay for different types of vegetables (unlabelled and labeled) were determined though multiple regression analysis as per Field (2005).

$$
Y=B_{0}+B_{1} X_{1}+B_{2} X_{2}+B_{3} X_{3}+B_{4} X_{4}+B_{5} X_{5}+\varepsilon
$$

Where, $\mathrm{Y}$ is the dependent variable (here, AWTP measured in NRs)

$B_{0}$ is the intercept and $B_{1}, B_{2}, B_{3}, B_{4}$ and $B_{5}$ are the slope parameters of the model

$X_{1}$ years of education, $X_{2}$ age of the respondents, $X_{3}$ monthly family income (in NRs)

$\mathrm{X}_{4}$ respondents' status (dummy), i.e. engaged in job or not $(1=$ have job, 0 otherwise)

$X_{5}$ family size, $\varepsilon$ error term

\section{RESULTS AND DISCUSSION}

\section{UNDERSTANDING ABOUT ORGANIC AGRICULTURE}

Though more than 50\% of farmers expressed that they have heard of and known about organic farming, different farmers do have different levels of knowledge (Figure 1). Some farmers especially who are far from market centre and infrastructure have even not heard about organic farming. This envisages spatial difference in terms of organic farming development. Most of the producers are of the view that organic agriculture is chemical free production practice; some asserted that they are produced only using manure as fertilizer source. Along with that some considered organic farming as product of natural/traditional agriculture. Within this variability of knowledge about organic agriculture, farmers are found managing their farm as per their level of knowledge and skills. In some areas, it has been evident that they use modest amount of inorganic fertilizers and use huge amount of organic manure and name this practice as organic ones. Integrated pest management (IPM) has also considered organic farming in some areas. Variation in knowledge about organic farming is obvious because of lack of extension that deciphers the knowledge and skills of this farming method. Organic farming is the technique which calls for extension of knowledge vis-à-vis skills among the end users. Unfortunately government extension service remains quite rudimentary in the study area despite its peri-urban location. As a matter of fact many farmers have only vague ideas about organic farming and its advantages as against the traditional and modern farming methods. Albeit many farmers have been involved in organic production, their way of managing organic farm may not justify organic standards. 


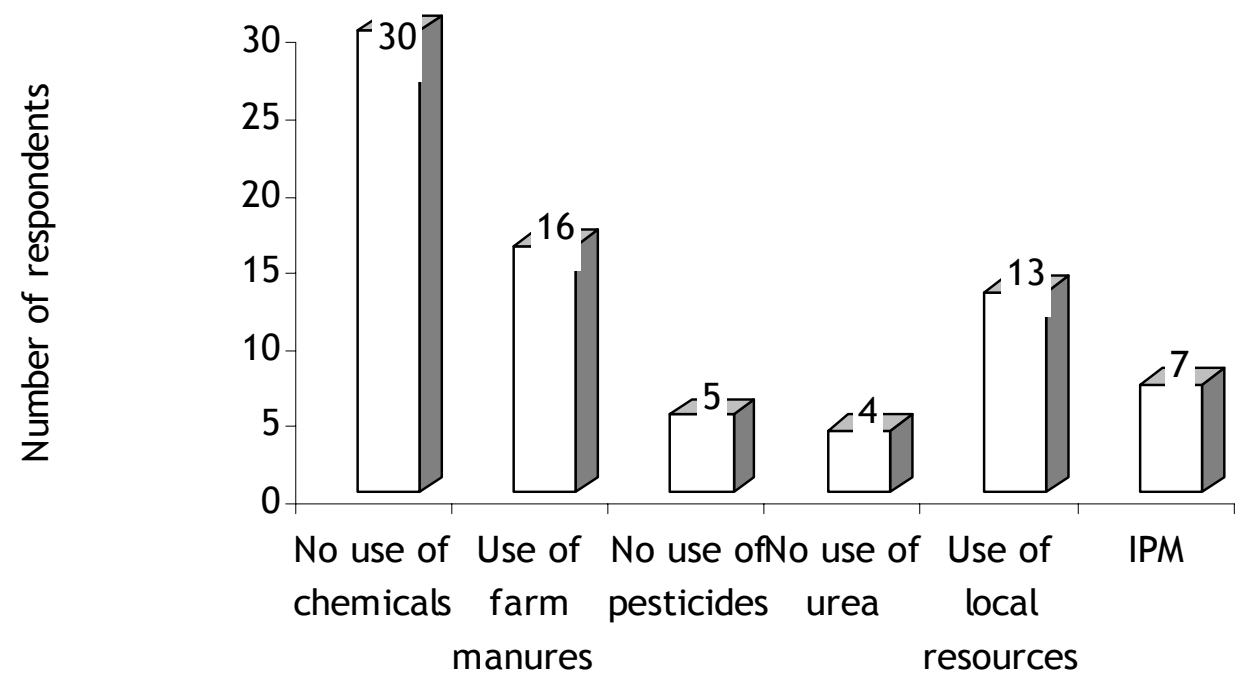

Farmers' understanding of organic farming

Figure 1. Farmers' definition towards organic farming

Similarly majority of the consumers replied that they had heard of organic vegetables and known the significance of it, however, most of them lack knowledge about their availability. This finding is in concordance with that of Sharma (2005) who reported that $63 \%$ of the respondents knew about organic products while $37 \%$ of the respondents did not. This indicates that awareness programs about organic products could be an effective way of promoting organic products among consumers. Piyasiri and Ariyawardana (2002) have also advocated that organic product marketers should develop awareness programs aiming supermarket shoppers in order to promote consumer-buying behavior.

\section{MARKETING PRACTICES}

Two most prominent practices exist in selling organic vegetables in the Kathmandu valley. They are sold directly through producers and through middlemen (Figure 2). In case of direct selling consumers come to the farm gate and buy vegetables and this is not very common. Another practice is that producers deliver the products to the consumers, common for the affluent consumers who are ready to pay more.

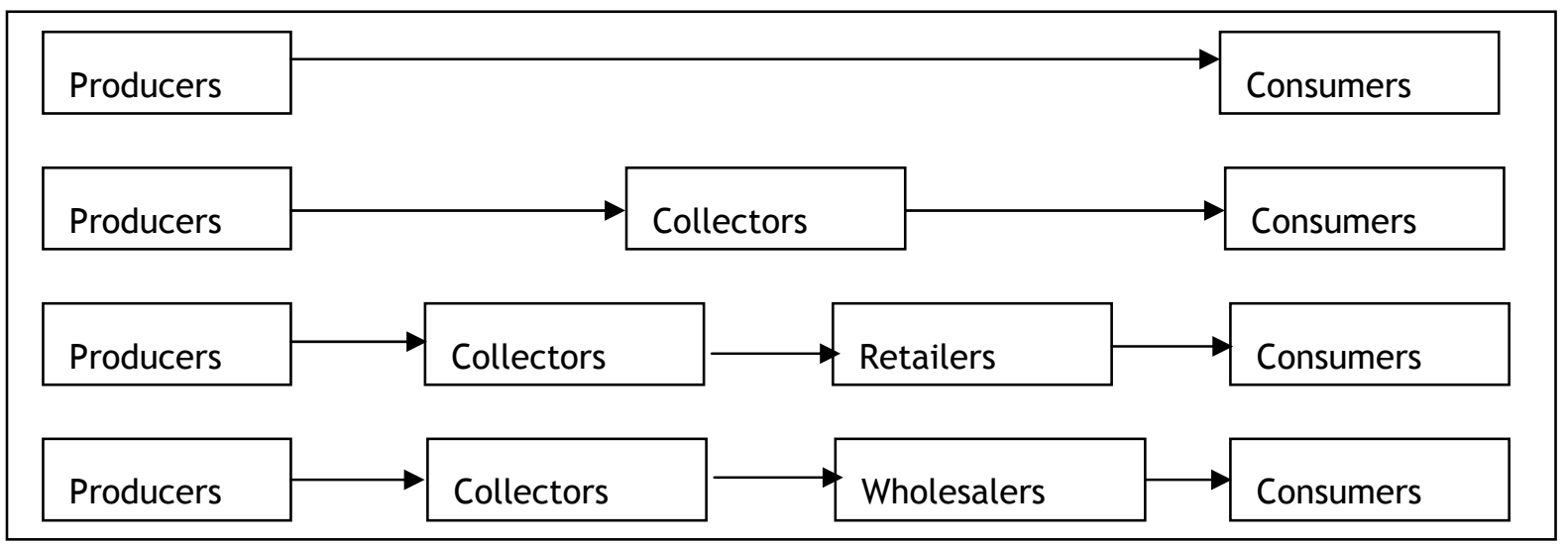

Figure 2: Common marketing channels for organic vegetables in the Kathmandu valley 
Both of these practices promote the direct distribution of products from farm to consumer, and are based on the principle of the producers and consumers "shaking hands" and 'supporting each other'. In another case some middlemen perform the job of collection of organic vegetables from the producers and they do perform the job of marketing either by delivering to the consumers' place or selling to the specialized shops. Albeit depicted, very seldom does other marketing channel of organic vegetables exist. Nevertheless, it is much likely, in the future, that complex marketing channel will take momentum.

\section{CONSUMPTION OF DIFFERENT TYPES OF VEGETABLES}

Consumers' personal attributes and consumption of three vegetables viz., tomato, cauliflower and broadleaved mustard have been analyzed.

Consumption of organic, inorganic and both types of tomato has been cross tabulated with educational levels of the respondents (Table 1) and it was evident that majority of the respondents with university degree consumed organic tomato and it was significantly different as per educational levels $(P<0.01)$. The typical organic consumer belongs to the higher educated, higher income strata, often having young children (FAO, 2001).

Table 1. Educational levels and consumption of different types of tomato

\begin{tabular}{lllllll}
\hline \multirow{2}{*}{$\begin{array}{c}\text { Tomato } \\
\text { Type }\end{array}$} & \multicolumn{1}{c}{$\begin{array}{c}\text { No formal } \\
\text { education }\end{array}$} & Primary & Secondary & $\begin{array}{c}\text { Higher } \\
\text { secondary }\end{array}$ & Total \\
\cline { 2 - 6 } & 1 & 0 & 0 & 1 & 26 & 28 \\
\hline Organic & 4 & 5 & 3 & 10 & 22 & 44 \\
Inorganic & 4 & 0 & 0 & 5 & 10 & 17 \\
Both & 2 & 5 & 3 & 16 & 58 & 89 \\
Total & 7 & & & & &
\end{tabular}

Chi-Square value $=19.224^{* *}$

**Significant at 0.01 level of probability

It is evident that most of the consumers with university degree consumed organic cauliflower (Table 2) and also broadleaved mustard. With the use of chi-square test, it is conspicuous that there was significant discrepancy $(P<0.05)$ between education and consumption of different types of cauliflower, however, it fails to show significant discrepancy in between consumption of different types of broad leaved mustard and levels of education.

Organic commodities are expensive by nature; therefore, not all the consumers can afford to buy them. The average Nepalese consumer is price-oriented and thus not prepared to pay a higher price for a product, which he/she does not perceive as 'better'. Therefore, personal and family incomes also play a crucial role in making decision about which type of products to be purchased. It is conspicuous that large numbers of the consumers with personal income more than NRs. 11,000 do consume organic tomato (Figure 3). Similar results have been attached with consumption of organic cauliflower and broadleaved mustard. This shows clear tendency in consuming organic vegetables by higher income group. Similar results have been obtained in consuming different types of vegetables as per family income. 
Table 2. Relation between education and consumption of different types of cauliflower

\begin{tabular}{lllllll}
\hline \multirow{2}{*}{ Cauliflower type } & \multicolumn{2}{l}{ Education levels } & \multicolumn{3}{l}{ Total } \\
\cline { 2 - 6 } & $\begin{array}{l}\text { No formal } \\
\text { education }\end{array}$ & Primary & Secondary & $\begin{array}{l}\text { Higher } \\
\text { secondary }\end{array}$ & University & \\
\hline Organic & 3 & 0 & 1 & 2 & 24 & 30 \\
Inorganic & 1 & 5 & 2 & 8 & 17 & 33 \\
Both & 3 & 0 & 0 & 6 & 14 & 23 \\
Total & 7 & 5 & 3 & 16 & 55 & 86 \\
\hline
\end{tabular}

Chi-square value $=16.920^{*}$

*Significant at 0.05 level of probability

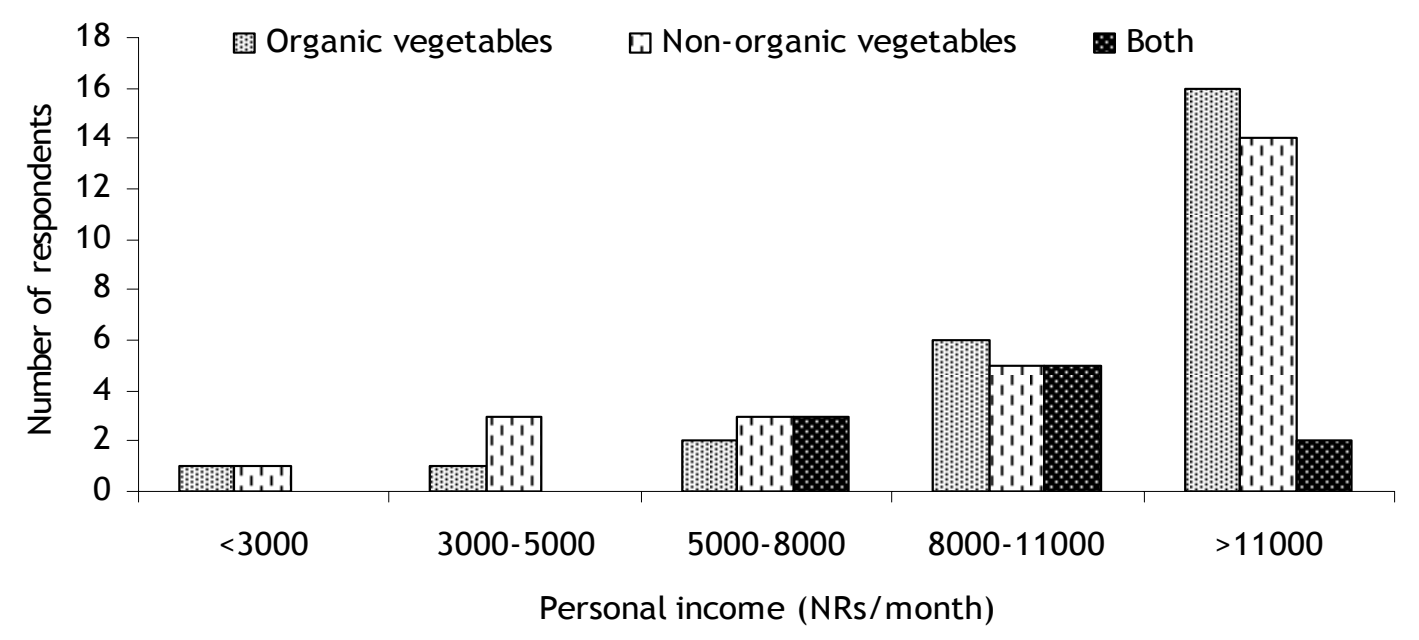

Figure 3. Personal income of the consumers and consumption of vegetables

\section{ADDITIONAL WILLINGNESS TO PAY (AWTP) ANALYSIS}

AWTP for organic vegetables values before and after labeling have been obtained by asking the respondents they would be willing to pay more rupees to the organic vegetables as compared to inorganic vegetables. Paired sample $t$ test indicates that there has been significant difference in terms of AWTP for labeled and unlabelled organic vegetables. The mean rupees consumers are willing to pay for unlabelled organic vegetables is NRs 5.07 per $\mathrm{kg}$ while that is $\mathbf{8 . 4 7}$ per $\mathrm{kg}$ NRs in case of labeled organic vegetables (Table 3 ). This conspicuously demarcates the importance of certification and labeling. A price premium of 20 percent over conventional products seems to be the maximum accepted in many countries. Market studies show that majority of the consumers of Denmark would like to pay 10\% extra for organic food, in France $30-35 \%$ and in Japan 10-20\% (FAO, 2001). Misra et al. (1991) estimated that $40 \%$ of consumers would be willing to pay $10 \%$ more for a product free of pesticide residues, while Weaver et al. (1992) calculated that around 50\% would pay at least $10 \%$ more for pesticide-free tomatoes.

A majority of the consumers are willing to pay or paying almost five rupees more to the unlabelled organic vegetables over inorganic while the percentage of consumers decreases with the higher range of additional price for unlabelled organic vegetables (Figure 4). AWTP would have been remarkably different if organic vegetables had been labeled. A majority of the consumers would be willing to pay five to 10 rupees per $\mathrm{kg}$ of labeled organic vegetables by those who are willing to pay less than five rupees per $\mathrm{kg}$ for 
unlabeled organic vegetables. Percentage of consumers willing to pay 10-15 and 15-20 rupees per $\mathrm{kg}$ of labeled organic vegetable is higher than that of the unlabelled counterpart. Labeled food products show all the information needed which is fundamental to give credence to the product. This could be done through certification and concomitantly through labeling. Certification process is expensive venture. Therefore, certified organic products are expensive. The consumers who have understood this reality would be willing to pay more premium for certified and labeled organic vegetables so that they have not to wonder whether the vegetables they consume is really organic.

Table 3. Summary of the AWTP

\begin{tabular}{llll}
\hline Organic vegetables & Mean AWTP $($ NRs $/ \mathrm{kg})$ & t-Ratio & p-value \\
\hline Without label (present situation) & $5.07(4.61)$ & -30.423 & 0.000 \\
With label (assumed situation) & $8.47(4.60)$ & & \\
\hline
\end{tabular}

Values in the parenthesis indicate standard deviation

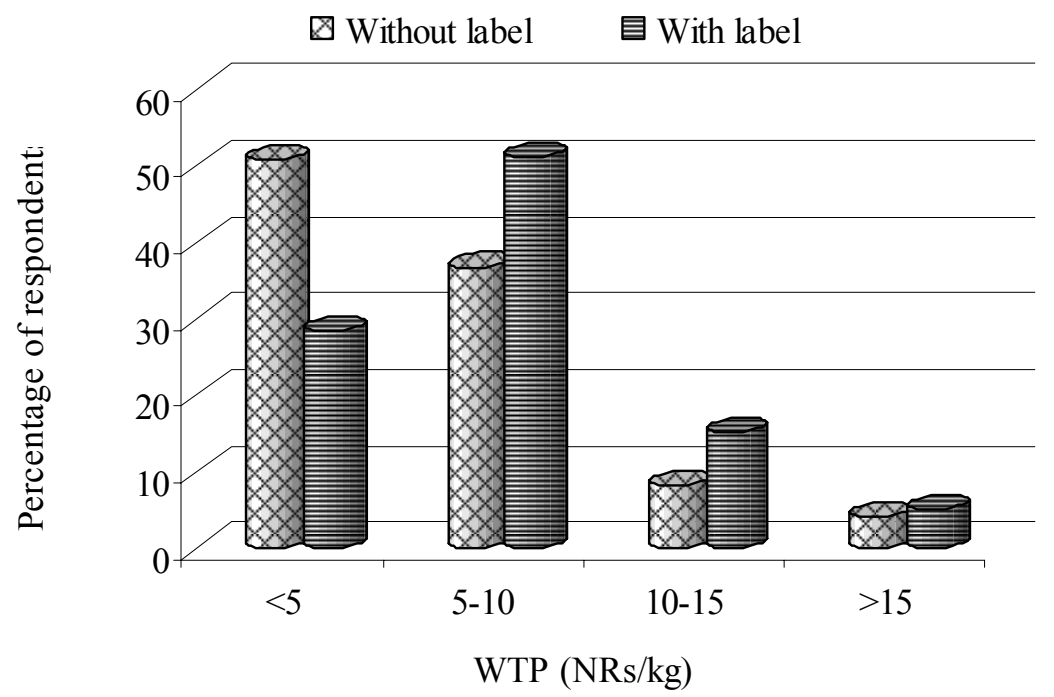

Figure 4. AWTP for organic vegetables before and after labeling

\section{FACTORS INFLUENCING THE AVERAGE AWTP FOR ORGANIC VEGETABLES}

Results of regression analysis depict that almost $58 \%$ and $63 \%$ of the total variation of the average AWTP for unlabelled and labeled organic vegetables respectively has been determined by the independent variables under study. Independent variables such as education and the involvement of the consumers in job or their enterprises are highly significant while family income is significant. Therefore, purchase decision of organic vegetables and willingness to pay has been governed by the personal and family income and level of education of the consumers. Same independent variables are found significantly contributing towards average AWTP for organic vegetables after being labeled. An increment of family income by 1000 NRs per month would increase average AWTP by NRs 0.116 for unlabelled organic vegetables and 0.111 for labeled organic vegetables (Table 4) compared to inorganic counterparts while keeping all other factors constant. 
Table 4. Multiple regression results (Dependent variable is AWTP NRs)

\begin{tabular}{lllllll}
\hline Variables & \multicolumn{2}{l}{ Coefficients } & \multicolumn{3}{c}{ t- Ratio } & \multicolumn{3}{c}{-value } \\
\cline { 2 - 7 } & $\begin{array}{l}\text { Without } \\
\text { label }\end{array}$ & $\begin{array}{l}\text { With } \\
\text { labeling }\end{array}$ & $\begin{array}{l}\text { Without } \\
\text { label }\end{array}$ & $\begin{array}{l}\text { With } \\
\text { labeling }\end{array}$ & $\begin{array}{l}\text { Without } \\
\text { label }\end{array}$ & $\begin{array}{l}\text { With } \\
\text { labeling }\end{array}$ \\
\hline Education & 0.322 & 0.401 & 3.944 & 5.234 & $0.000^{* *}$ & $0.000^{* *}$ \\
Age & -0.002 & 0.019 & -0.057 & 0.668 & 0.955 & 0.506 \\
Family Income('000 NRs) & 0.116 & 0.111 & 2.466 & 2.514 & $0.016^{*}$ & $0.014^{*}$ \\
Engagement & 3.892 & 3.657 & 5.184 & 5.190 & $0.000^{* *}$ & $0.000^{* *}$ \\
Family size & -0.070 & -0.038 & -0.498 & -0.297 & 0.620 & 0.772 \\
Intercept & -3.223 & -1.568 & -1.563 & -0.810 & 0.122 & 0.420 \\
\hline $\mathrm{R}^{2}=0.579, \mathrm{AdjR}^{2}=0.554 \mathrm{~F}=23.067 \mathrm{p}$-Value $=0.000 \mathrm{~N}=90$ (For unlabelled organic vegetables) \\
$\mathrm{R}^{2}=0.630, \mathrm{AdjR}^{2}=0.608 \mathrm{~F}=28.599 \mathrm{p}$-Value $=0.000 \mathrm{~N}=90$ (For labeled organic vegetables) \\
\hline
\end{tabular}

Note. ${ }^{*},{ }^{* *}$ Significant at 0.05 and 0.01 level of probability respectively

One of the consumers' behavior studies conducted in Argentina and Denmark reports that organic consumers belong to relatively higher income strata, have knowledge about organic products and their quality and they are health conscious (FAO, 2001). Preference of buying organic vegetables by higher income group is obvious as organic products are relatively expensive but with high quality. So high income coupled with knowledge about health and consumption of quality products could motivate consumers to opt for organic consumption.

\section{SWOT ANALYSIS}

This section analyzes the Nepalese organic sector using SWOT-analysis: Strengths, Weakness, Opportunities and Threats. It provides the sector's strengths and successes, but also lists limiting factors.

\section{Strengths}

Organic production is feasible virtually throughout the country, without major adjustments to traditional production methods. Organic seed production, vegetable production, fruits production etc could be made easy under such a diverse topography, soil and climatic situations. Thanks to physical conditions that made this possibility easy. Direct market linkage with India could be other strength. Organic production has been started by the farmers themselves without government intervention. Commercial production under such private initiation could be not very difficult as these initiators have awareness and knowledge of organic farming. Market development, gradually increasing consumers' awareness about health and quality along with preference towards quality food products could provide better return to the producers. Emphasis given to the organic farming and certification in National Agriculture Policy 2061 is good strength of this sector.

\section{Weaknesses}

There exist some weaknesses limiting farmers' ability to take full benefit out of the above-mentioned strengths. Farmers' ability to invest is far below and there is virtually no support from the government in this arena. There is also dearth of technology in organic sector and many producers complain about the limited availability of bio-pesticides. 
The organic sector is in embryonic stage while extension services are relatively hibernated resulting in lower than expected yields, especially during the initial years of production. Many producers start producing organically on a 'trial and error' basis, and adjust their farming methods every season until they reach an acceptable and stable level of output. Unfortunately no government support exists during the period of conversion, a practice that is common in, for example, many European countries in order to provide incentives to farmers to convert and keep them going ahead. Although number of organic consumers is increasing gradually these days, the number is still limited to justify commercial production with certification.

When deciding on whether to go for organic production and conversion thereafter, one should have a close scrutiny of different production and management methods needed in order to succeed. The generally needed conversion period of three year makes long-term planning indispensable. For such planning, a careful cost-benefits analysis should be carried out. However, none of the farmers have been found doing this. Mostly farmers do have small area under cultivation and it is uneconomical for small farmers to practice commercialization of the production. Furthermore, organic certification, which has yet to be practiced in Nepal, is too costly for small farmers to pay for it.

\section{Opportunities}

There exists good opportunity for organic farming in the urban and peri-urban areas of the country as most of the affluent consumers have been agglomerated around cities and cities are the popular destinations for the tourists. Some specialized markets have started selling organic products and some are willing to start selling organic products. There is immense scope for the organic products to be delivered to India and other countries provided quality standards have been maintained.

Growing awareness among the educated circle and increasing purchasing power could provide the ramification towards organic farming development. Organic farming requires more labour input than traditional and modern farming methods. Thus, Nepal which has a very large amount of labour unemployment and under employment will find organic farming an attraction. Moreover, the problem of periodical unemployment will also get mitigated because of the diversification of the crops with their different planting and harvesting schedules resulting in the requirement of a relatively high labour input. Ecotourism is increasingly becoming popular and organic farms could turn into favourite spots. Protection of the ecosystem, flora, fauna and increased biodiversity and the resulting benefits to all human and living things are great advantages of organic farming which are yet to be properly accounted for.

\section{Threats}

One obvious threat factor is competition from other countries with similar advantages especially India. As Indian government provides subsidy to the farmers and they could produce same quality product in less cost and it is likely that such products could intrude Nepalese market.

Nepalese political situation is also one of the major threats in putting debar to the organic movement. Relentless government, lack of policies, weak governance system etc are exacerbating problem. No guarantee on the price of organic products is another threat to the organic growers. Until and unless farmers are assured with the handsome price of the organic products, farmers will not be motivated anymore and asking them to go through organic production remains another threat. 


\section{CONCLUSION}

The interest in organic agriculture in developing countries is growing because it places more reliance on the natural and human resources available. Possibly, the greatest impact of organic agriculture is on the mindset of people. It uses traditional and indigenous farming knowledge, while introducing selected modern technologies to manage and enhance diversity, to incorporate biological principles and resources into farming systems, and to ecologically intensify agricultural production. By adopting organic agriculture, farmers are challenged to take on new knowledge and perspectives, and to innovate. This leads to an increased engagement in farming which can trigger greater opportunities for rural employment and economic upliftment. Thus through greater emphasis on use of local resources and self-reliance, conversion to organic agriculture definitely contributes to the empowerment of farmers and local communities.

Nepalese organic sector has been growing but in a sluggish manner. Private initiation and motivation by some of the NGOs are the key impetus in bringing organic sector in the mainstream agriculture development in Nepal. There is virtual lack of government support to the organic growers and marketers. It is found that before beginning cultivation of organic crops, their marketability and that too at a premium over the traditional and modern produce has to be assured. Inability to obtain a premium price, at least during the period required to achieve the productivity levels of the conventional crop will be a setback. High prices of these products remain a major deterrent for consumers. The constraints could be seen in three actors of organic production viz., at growers' level, marketers' level and government's level. Lack of awareness, lack of skills in managing complex problem in the farm land, lack of sufficient organic technology to support production, no certification and labeling, poor investment capacity, small holding, less risk bearing capacity etc are the key constraints at the growers' level. Lack of consumers' awareness about the organic products, quality and availability, lack of trust about the authenticity of the products, higher price of the products, lack of market infrastructure, no market regulation etc are the constraints at marketers' level. Failure to hammer out proper policy and poor implementation mechanism, political intervention, no subsidy to the farmers, no marketing research and technology generation to support organic sector etc are the constraints at the government's level. Despite these constraints, Nepal has ample opportunities to promote organic sector owing to its physical and natural endowment, prevailing farming practice, increasing economic profile and human and environmental health awareness and tourist destination. Although this research could open avenue for policy makers to consider key aspects in hammering policy and also for researchers to initiate further studies, there is also need to conduct research in the marketing segment as well to capture diversified consumers and benefit growers and marketers wherefrom.

\section{ACKNOWLEDGEMENT}

Financial support provided by the German Academic Exchange Service (DAAD) to carry out this study is highly acknowledged. The authors owe deep sense of appreciation to Mr. Govinda Sharma for his invaluable information and the farmers, consumers and the traders for their time, inputs and responses during field study.

\section{REFERENCES}

Bhatta, G.D., W. Doppler and K. B. KC, 2008a. Problems and potentials of organic agriculture development in Nepal. In: International Research on Food Security, Natural Resource Management and Rural Development. October 7-9, 2008, Hohenheim University, Stuttgart, Germany. Organized by Deutscher Tropentag 2008. 
Bhatta, G. D., A. Ranabhat and M. Subedi, 2008b. Consumer's awareness and willingness to pay for organic vegetables in the Kathmandu Valley. Green Field Journal of Himalayan College of Agricultural Sciences and Technology, 6(1):52-61.

Bower, J. and I. Baxter, 2000. Consumer Perception of the Nature and Quality of Home-made and Commercial Dairy Ice Cream. British Food Journal, 102(11):821-837.

Boyle, P.J. and E.S. Lathrop, 2009. Are consumers' perceptions of price-quality relationships well calibrated? International Journal of Consumer Studies, 33:58-63.

Elliott, G. and R. Cameron, 1994. Consumer Perception of Product Quality and the Country-ofOrigin Effect. Journal of International Marketing, 2(2):49-62.

FAO, 2001. World markets for organic fruit and vegetables - Opportunities for developing countries in production and export of organic horticultural products. International Trade Centre (ITC), Technical Centre for Agriculture and Rural Cooperation, Food and agriculture Organization of the United Nations (FAO), Rome.

Field, A., 2005. Discovering statistics using SPSS. Sage Publications, New Delhi.

Fotopoulos, C. and A. Krystallis, 2002. 'Organic product avoidance: reasons for rejection and potential buyers' identification in a country-wide survey’. British Food Journal, 104(3-5):233260.

Kotler, P., 2001. Principles of Marketing. $5^{\text {th }}$ Ed. Irwin, McGraw-Hill, Boston.

Lampkin, N., 1990. In Acs, S; P.B.M. Berentsen and R.B.M. Huirne (Eds.) Modelling conventional and organic farming: a literature review. NJAS, 53(1), 2005.

Lans, I.; K. Ittersum; A. Cicco and M. Loseby, 2001. The Role of the Region of Origin and EU Certificates of Origin in Consumer Evaluation of Foods Products. European Review of Agricultural Economics, 28(4):451-477.

Misra, S., C. Huang and S. Ott, 1991. Consumer willingness to pay for pesticide-free fresh produce. Western Journal of Agricultural Economics, 16:218-227.

Okechuku, C. 1994. Importance of Product Country of Origin: A Conjoint Analysis of the United States, Canada, Germany and the Netherlands. European Journal of Marketing, 28(4):5-19.

Piyasiri, A. G. S. A. and A. Ariyawardana, 2002. 'Market potentials and willingness to pay for selected organic vegetables in Kandy'. Sri Lankan Journal of Agricultural Economics. 4(1):107119.

Ramesh, P; M. Singh and A. Subba Rao, 2005. Organic farming: Its relevance to the Indian Context. Current Science, 88(4):33-40.

Roddy, G., C. A. Cowan and G. Hutchinson, 1996. 'Consumer attitudes and behavior to organic foods in Ireland'. Journal of International Consumer Marketing, 9(2):41-63.

Senauer, B., 1994. Evolution of an Industrialized, Globalized, Consumer-Driven Food System. Fourth Minnesota Padova Conference on Food Agriculture, and Environment, September 4-10.

Sharma, A.K., 2001. A Handbook of Organic Farming, Agrobios (India), Jodhpur.

Sharma, G., 2005. Organic Agriculture in Nepal: An Analysis in to Status, Policy, Technology and Psychology." In: Sharma, G. and P.B. Thapa (Eds.) Proceeding of National Workshop on Organic Agriculture and Food Security, December 13-15, 2005, Kathmandu, Nepal.

Veeresh, G.K., 1999. Organic Farming Ecologically Sound and Economically Sustainable, Plant Horti Tech, 1(3).

Weaver, R.D., D.J. Evans and A. Luloff, 1992. Pesticide use in tomato production consumer concerns and willingness to pay. Agribussiness, 8:131-142. 